\title{
Trade Rules for Industry 4.0
}

\section{Why the Technical Barriers to Trade Agreement Matters Even More}

\author{
Aik Hoe Lim*
}

\section{INDUSTRY 4.O: THE WHOLE IS GREATER THAN THE SUM OF ITS PARTS}

Aristotle is credited for having said "the whole is greater than the sum of its parts". Correctly or incorrectly attributed to Aristotle, those words have beguiled philosophers for many a century. If Aristotle did indeed say those words, ${ }^{1}$ he probably did not have Industry 4.0 in mind.

Yet, his thoughts are rather prescient. They are prescient in the sense that the concept that "the whole is greater than the sum of its parts" underpins the notion of "emergence", a key idea in the debate over what is consciousness and artificial intelligence (AI). ${ }^{2}$ It is indeed a very good description of what we are witnessing with the convergence ${ }^{3}$ of $\mathrm{AI}$, robotics, additive manufacturing ( $3 \mathrm{D}$ printing), blockchain and the Internet of Things (IoT) into digitally connected networks of production, communication and consumption. The effects of technological innovation are creating immense transformations in the way companies and countries organize production, trade goods, invest capital and develop new products and processes.

The third industrial revolution brought us the power of the microprocessor and the personal computer with the capacity to store, organize and retrieve vast amounts of data, and undertake cumbersome repetitive tasks in milliseconds. As each

This chapter is based on my keynote address at the 6th Biennial Conference of the Asian International Economic Law Network: "International Trade Regime for the Data-Driven Economy: How Will Artificial Intelligence Transform International Economic Law?” (26-27 October 2019, Chinese Taipei). The views expressed are mine and cannot be attributed to the World Trade Organization, the Secretariat or its members. I am grateful to Lauro Locks, Devin McDaniels, Mateo Ferero and Maryam Aldoseri for their comments and assistance in undertaking background research.

1 Even if not that exact phrase, Aristotle's writings do indeed seem to indicate he was perhaps the first to introduce this very idea. See "No, Aristotle Didn't Write 'A Whole Is Greater Than the Sum of Its Parts"' (Sententiae Antiquae, 6 July 2020), https://perma.cc/JD7N-HKZW.

$=$ See B Reese, The Fourth Age: Smart Robots, Conscious Computers, and the Future of Humanity (New York, Atria, 2018), at 52, 71; and M Tegmark, Life 3.o: Being Human in the Age of Artificial Intelligence (London, Penguin Books, 2017), at 300.

3 See generally R Baldwin, The Great Convergence: Information Technology and the New Globalization (Cambridge, MA, The Belknap Press of Harvard University Press, 2016). 
"disruptive technology"4 improved on the hardware and software of computing, the costs of PC ownership were rapidly brought down, giving households access to computing power previously only enjoyed by large institutions. By connecting individual computers together in the worldwide web, the Internet was created, and a new paradigm of communication and data became possible. And this continuing acceleration of technological deployment is now coupled with an equally rapid process of diminishing costs. Indeed, it has been estimated that "[b]efore 2050, the price of a computer with the computational power of everyone on the planet combined will be less than what you paid for your smartphone in 2018 ". 5

The fourth industrial revolution and Industry $4.0^{6}$ extends this march of technology as digital networks of hardware and software become more sophisticated and integrated. Fueled by data and algorithms, and aided by sensors, machines and computers can autonomously communicate with each other, and are increasingly doing tasks and taking decisions without human involvement. ${ }^{7}$

Take the modern car, which is fast resembling a computerized hub of sensors with wheels. Fully or semiautonomous vehicles collect, exchange and analyze data that is then used to take decisions that can be better or faster than the human brain: braking before a collision, shifting from two to four wheels or, in the ultimate case, driving itself. And the amount of data that can be collected is immense: it has been estimated that "a single car will generate about as much data as 3,000 people do in a similar period day". ${ }^{8}$ All this data can in turn be fed back into the production process to design better hardware, software and algorithms.

The same model of data connectivity, convergence and advanced analytics is being applied to heavy machinery, health equipment, buildings, consumer devices, logistics, supply management and so forth. Customers on e-commerce platforms generate vast amounts of data, which AI can use to better anticipate consumer demand and behavior. A German online retailer that uses machine learning algorithms to predict what customers are going to buy has developed a system so reliable

4 World Trade Organization (WTO), "World Trade Report 2018: The Future of World Trade - How Digital Technologies Are Transforming Global Commerce" (2018(hereinafter WTO 2018) ), https:// perma.cc/EV7G-QVJH, at 158 ("New disruptive technologies are affecting firm production decisions and reshaping global patterns of trade and investment").

5 Reese, note 2 above, at 188 .

6 "Industry 4.0" (Wikipedia), https://perma.cc/87K8-3AYL ("Industry 4.0 is the subset of the fourth industrial revolution that concerns industry .... Although the terms 'industry 4.0 ' and 'fourth industrial revolution' are often used interchangeably, 'industry 4.0' factories have machines which are augmented with wireless connectivity and sensors, connected to a system that can visualise the entire production line and make decisions on its own"). On the fourth industrial revolution more generally, see K Schwab, The Fourth Industrial Revolution (Geneva, World Economic Forum (WEF), 2016).

7 For a general overview of the different industrial revolutions, see Schwab, note 6 above, at 11-13. See also E Schulze, "Everything You Need to Know about the Fourth Industrial Revolution" (CNBC, 22 January 2019), https://perma.cc/N6X4-59EZ.

8 T Wheeler, From Gutenberg to Google (New York, Brookings Institution Press, 2019), at 224. 
that it can predict with 90 percent accuracy what will be sold within the following thirty days. ${ }^{9}$

Industry 4.0 is rapidly demonstrating that the whole is indeed greater than the sum of its parts. And it is in ensuring that the "whole" does come together that the World Trade Organization (WTO) Agreement on Technical Barriers to Trade (TBT) has a key role to play.

The TBT Agreement addresses regulatory interventions that may affect trade in products. This will be the case for many Industry 4.O-related standards and regulations. The unparalleled speed and breadth of the current "revolution" unfolds every day with new digital products being invented ready to fulfill needs we did not even know we had. These developments invariably expose a "dark side" of new technology; of risks that we also did not know could even exist. You may have heard that "IoT toasters" may be misused and turned into "weapons of mass destruction". Are such concerns far-fetched or legitimate? If they are legitimate, how should such concerns be regulated? Could governments be tempted to influence the evolving global governance framework through setting regulations that give their industry a first mover or competitive advantage?

The TBT Agreement, by promoting global regulatory coherence (harmonization via international standardization) and global regulatory cooperation (via good regulatory practices, equivalence and mutual recognition), will assume even greater importance as standards and regulations are developed for Industry 4.o. As the 2020 World Trade Report notes:

Cooperation on technical standards is also especially important when confronting novel regulatory challenges and risks, such as those related to "dual use technologies" (i.e. both for civil and defence purposes) or to the area of AI. Technical standards applying to dual-use technologies, for instance with respect to radio, telecommunication and network security, or autonomous vehicles and aircraft, are notified by WTO members under the TBT Agreement. ${ }^{10}$

More than ever, we will need to ensure that the interconnectivity and interoperability ${ }^{11}$ required by Industry 4.0 are not hampered by discriminatory or unnecessarily divergent standards and regulations.

9 “How Germany's Otto Uses Artificial Intelligence" (The Economist, 12 August 2017), https://perma.cc 16LTL-UUJJ.

10 World Trade Organization (WTO), "World Trade Report 2020: Government Policies to Promote Innovation in the Digital Age" (2020), at 137 (original footnotes omitted). www.wto.org/english/res_e/ booksp_e/wtrzo_e/wtrzo_e.pdf (hereinafter WTO 2020).

${ }^{11}$ Indeed, "[a] lack of international standards for the development of smart manufacturing can limit the interconnection of distributed manufacturing facilities and services, hampering export opportunities. Inefficient customs procedures, barriers to express delivery services, and tariffs also raise the costs of exporting goods that are purchased on digital platforms". J Meltzer, "Governing Digital Trade" (2019) 18 World Trade Review 23, at 36-37. 


\section{HOW WILL INDUSTRY 4.O IMPACT TRADE?}

WTO's 2018 World Trade Report ${ }^{12}$ explored some of the most immediate changes that we can envisage for the near future and concluded that new technologies have the potential to profoundly transform: (1) the way we trade; (2) who trades; and (3) what is traded. Understanding how these technologies may impact world trade is essential to thinking about the role of trade rules in maximizing gains and minimizing friction. ${ }^{13}$

Firstly, on the way we trade, we have seen the impressive rise of e-commerce, which has reshaped what and how we purchase and consume. In 2016, the value of e-commerce transactions was estimated to be US\$27.7 trillion, of which US\$23.9 trillion was business-to-business e-commerce transactions. ${ }^{14}$ The convergence of physical and digital worlds will create new economic opportunities, many of which have not yet been conceived. McKinsey forecasts that the IoT will add between US\$2.7 trillion and US\$ 6.2 trillion in economic value annually through 2025 and improve manufacturing productivity by up to 5 percent. Cisco estimates that the IoT will have a global economic impact of US\$ 14.4 trillion between 2013 and $2022 .{ }^{15}$

Secondly, advances in the way we trade will also reduce international trade costs. ${ }^{16}$ WTO projections predict that trade could grow yearly by $1.8-2$ percentage points until 2030 as a result of falling trade costs, amounting to a cumulated growth of 31-34 percentage points over fifteen years. Gains are expected to come in several ways: ${ }^{17}$

- Cargo and transport logistics are optimized by the combination of vehicle telematics, robotization and AI. IoT $^{18}$ sensors, for example, can reduce the costs of global trade by increasing the efficiency of transport and logistics. By

12 WTO 2018 , note 4 above.

13 For a recent comprehensive study on how trade rules (including those under the TBT Agreement) relate to innovation in the digital age, and how they reinforce and affect each other, see WTO 20zo, note 10 above.

14 In 2017 , global e-commerce transactions generated \$29.267 trillion, including \$25.516 trillion for business-to-business transactions and $\$ 3.851$ trillion for business-to-consumer sales. "Global E-commerce Sales Surged to \$29 Trillion" (UNCTAD, 29 March 2019), https://perma.cc/WQA7$36 \mathrm{H}_{7}$.

15 E Gerwin, "Industry 4.o: Trade Rules for the Internet of Things" (TradeVistas, 22 June 2017), https:// perma.cc/79D6-2UYV.

16 B Lewis, "How to Tackle Today's II Security Risks" (ISO, 10 January 2019), https://perma.cc/M2LQ$453 \mathrm{~V}$. See also J Meltzer, "A WTO Reform Agenda: Data Flows and International Regulatory Cooperation" (2019), https://perma.cc/ASQ7-7655, at 4 (stating that "E-commerce provides a potentially significant opportunity to increase small business participation in international trade. For instance, having a website gives small businesses an instant international presence without having to establish a physical presence overseas").

17 WTO 2018 , note 4 above.

18 As noted by the Organisation for Economic Co-operation and Development (OECD), there is no single, established global definition for "IoT". For a new overarching IoT definition, see OECD, "IoT Measurement and Applications" (2018), https://perma.cc/F2WC-4AGN, at 5. 
being able to track in real time, fewer goods will be lost in transport. Companies will also be able to optimize routes to efficiently use shipping containers. ${ }^{19}$

- The automation of warehousing, trailer and container unloading and packing will add to time and cost savings. Combined with AI algorithms, the use of advanced robotics minimizes the cost of storage and speeds up distribution to final customers. ${ }^{20}$

- It is not just transport and logistics that affect cross-border trade. Layers of procedures and customs regulations can add to costs. At the most basic, information and communications technologies (ICTs) can help reduce paperwork, streamline procedures and reduce the costs of crossing borders. In more advanced applications, $\mathrm{AI}$ is already being used to help businesses to continually monitor, analyze and comply with regulatory changes. ${ }^{21}$

- Harnessing blockchain's decentralized, distributed digital ledger that is secured using various cryptographic techniques could help improve trust. Information, once added to a blockchain, is time-stamped and cannot be easily modified, making it easy to track attempted changes, and transactions are recorded, shared and verified on a peer-to-peer basis by anyone with the appropriate permissions. While much of its potential is yet to be fully realized, it is expected that this technology could help the trading community to better access information and gain trust in cross-border transactions, which would in turn reduce the cost of transactions. ${ }^{22}$

Thirdly, the Internet and the reduction of trade costs has made trade more inclusive and reduced some of the challenges of size and geography. Services offered by online platforms have, for instance, facilitated the direct participation of micro, small and medium enterprises in export activities. The decline in information and transaction costs can help firms in developing countries that tend to face higher costs for obtaining information and guaranteeing transactions. The WTO estimates foresee that developing countries' share in global trade could grow from 46 percent in 2015 to 57 percent by $2030 .{ }^{23}$ Much depends on whether appropriate complementary policies are put in place and challenges related to technology diffusion and regulation are addressed.

Fourthly, the composition of what is traded may change. ${ }_{3} \mathrm{D}$ printing - the key element of "additive manufacturing" - may paradoxically reduce trade in intermediate parts and components. This may mean further reductions in transport and

19 WTO 2018, note 4 above, at 68.

20 Ibid., at 67 .

21 Ibid., at 71 .

22 Ibid., at 7, 71-72. See also E Ganne, "Can Blockchain revolutionize international trade?” (2018), www .wto.org/english/res_e/booksp_e/blockchainrevi8_e.pdf; and, more recently, E Ganne and D Patel, "Blockchain and DLT in Trade: Where do we stand?" (2020), www.wto.org/english/res_e/booksp_e/ blockchainanddlt_e.pdf.

23 Ibid., at 5 . 
logistics costs, and a consolidation of global value chains as $3 \mathrm{D}$ printing is used to locally manufacture complex or customized inputs. In time, this could lead to a shift toward more digital and localized supply chains with reduced need for a back room where inventories are stored. ${ }^{24}$

IT has also allowed for the "digitalization" of certain goods, where physical products have been progressively replaced by digital equivalents. For example, the digital distribution of books, films and music has increasingly replaced physical transactions, a trend that is blurring the traditional boundary between trade in goods and trade in services. The importance of services in the composition of trade is expected to increase, with the share of services trade to grow from 21 percent to 25 percent by 2030. Trade in information technology products has tripled in the past two decades, reaching US\$ 1.6 trillion in 2016.25

Yet achieving the great promise of Industry 4.0 is neither guaranteed nor automatic. The great convergence promised by the IoT requires, not least, solutions to many technical and practical barriers. Different devices, software and siloed systems based on varying standards must be enabled to interconnect, interoperate and communicate securely. There are also significant numbers of different policy concerns - not only the obvious ones like human safety but also others like national security, cybersecurity, impacts on market concentration, privacy and the digital divide ${ }^{26}$.

\section{HOW CAN TRADE AND WORLD TRADE ORGANIZATION RULES HELP} SHAPE THE FUTURE?

These are very important questions that have a trade rules dimension. It is also a vast canvas of issues. At the WTO, in terms of existing rules, "WTO agreements reached a quarter of a century ago proved to be remarkably forward-looking in providing a framework that helped to foster the development of an ICT-enabled economy in countries across all levels of development, while preserving policy space for countries to pursue different models of digital development." ${ }^{27}$

In terms of new rules, at the WTO, much of the discussion has been on what rules are needed to support e-commerce. While e-commerce is not "new" in the WTO, lately there have been very active discussions, particularly under the "Joint

24 See "Global Value Chain Development Report 2019: Technological Innovation, Supply Chain Trade and Workers in a Globalized World" (2019), https://perma.cc/J6KV-XRUT, at 73.

25 WTO 2018 , note 4 above, at 5.

26 According to a recent WTO Secretariat note, the current COVID-19 pandemic "has highlighted the glaring need to bridge the digital divide, both within and across countries, given the central role the digital economy has played during the crisis". The Note also observed that, due to the pandemic, "[m]any traditional obstacles have been accentuated and have continued to hamper greater participation in e-commerce activities by small producers, sellers and consumers in developing countries, particularly in least-developed countries (LDCs)". "E-Commerce, Trade and the COVID-19 Pandemic - Information Note" (WTO, 4 May 2020), https://perma.cc/BFV8-J64U.

27 WTO 2020, note 10 above, at 11. 
Statement Initiative on E-commerce", currently involving some eighty-six WTO members. ${ }^{28}$

Under those discussions, text-based proposals are being discussed under five broad themes: digital trade facilitation and logistics; access to Internet and data; business trust; capacity building and cooperation; and market access. In these discussions, one key consideration has been on how cross-border data flows are affected by diverse localization, privacy and security requirements. Analyses of existing WTO rules that have relevance for e-commerce have tended to focus on the General Agreement on Trade in Services (GATS).

E-commerce in services encompasses not only the end-to-end electronic delivery of services, such as Internet and other telecommunications, themselves a service supplied electronically, but also the many other services that can be transmitted in digitized form. There are also online distribution services, such as e-commerce web portals, through which goods or services are ordered electronically, even if subsequently delivered in physical form. Some services sectors are, in themselves, part of the infrastructure for e-commerce. These include telecommunications and distribution services; postal and delivery services; financial services; and transport and logistics. While the GATS is clearly an important instrument in respect of e-commerce, I would like to take a different tack and reflect on the "goods" angle.

Industry 4.0 "smart manufacturing" means that goods are affected and improved by services as much as services are affected and improved by goods. Indeed, for some, this may even challenge the very definitions of, and boundaries between, goods and services, which in turn may impact assessing ed which specific WTO disciplines apply to measures affecting Industry $4 .{ }^{2}{ }^{29}$ Besides the GATS, a plethora of other

28 In January 2019, at the WEF in Davos, a group of 76 WTO members issued a joint statement confirming their "intention to commence WTO negotiations on trade-related aspects of electronic commerce" (WT/L/1056, 25 January 2020). As of December 2020, the number of participating members stood at eighty-six. In a recent statement, JSI participants informed that on 7 December 2020 they circulated among them a "consolidated negotiating text that captures progress so far" and that this text "will form the basis of the next stage of negotiations". They added that this "consolidated text" was "based on Members' proposals" covering the "following themes: enabling electronic commerce; openness and e-commerce; trust and e-commerce; cross-cutting issues; telecommunications; market access; and scope and general provisions". ("Joint Statement Initiative on E-Commerce: co-conveners' update", https://perma.cc/8HFV-9NU9). See also "E-commerce coconvenors release update on the negotiations, welcome encouraging progress" (WTO, ${ }_{14}$ December 2020), https://perma.cc/HW52-S66J and "Negotiations on e-commerce continue, eyeing a consolidated text by the end of the year" (WTO, 23 October 2020), https:/perma.cc/ESE2-7RGX. See further "E-Commerce, Trade and the COVID-19 Pandemic - Information Note" (WTO, 4 May 2020), https://perma.cc/BFV8-J64U.

29 See A Chander, "The Internet of Things: Both Goods and Services" (2019) 18 World Trade Review 9 (positing that if "IoT consists in goods, then the [GATT], as well as the [TBT Agreement], will discipline trade barriers to the flow of goods [but if] IoT consists in services, then the [GATS] will apply, though generally to different barriers than those covered by GATT"; and then concluding that, in fact, "IoT consists in both goods and services, therefore calling into application multiple WTO disciplines, with the specific agreements that are applicable dependent on the particular measure subject to challenge" (p. 3-emphasis added). See also Shin-yi Peng, "A New Trade Regime for the 
WTO disciplines may be at play here, ${ }^{30}$ including the TBT Agreement but also, among others, the General Agreement on Tariffs and Trade (GATT), Sanitary and Phytosanitary (SPS) Agreement (food safety and animal plant health), Trade Facilitation Agreement (TFA) (facilitating customs procedures), Trade-Related Aspects of Intellectual Property Rights (TRIPS) (intellectual property) ${ }^{31}$ and Import Licensing Agreement.

For the purpose of my chapter here, I will focus on the WTO's TBT Agreement. In doing so, I would like to reflect on some challenges and opportunities; in particular, on how the existing principles and disciplines in the TBT Agreement as well as practices and guidance developed by the WTO TBT Committee over the years are likely to be relevant for Industry $4.0 .3^{32}$

\section{A Coverage of Technical Barriers to Trade and Industry 4.0: Examples of Industry 4.o-Type Technical Barriers to Trade Notifications}

Recent notifications of draft regulations to the TBT Committee show that Industry 4.o-related regulations are increasing in number and variety, and that members, by submitting such notifications, consider them as falling within the scope of the TBT

Servitization of Manufacturing: Rethinking the Goods-Services Dichotomy" Journal of World Trade 54 , no. 5 (2020): 699-726 (stating that the "age of industry 4.0 " is witnessing "increasing complementarities between goods and services," which is in turn leading to government interventions (regulations) in this area that are increasingly of a "dual nature," thus leading to "problems related to the concurrent application of the goods/services trade rules"). See also P Sauvé, "To Fuse, Not to Fuse, or Simply Confuse? Assessing the Case for Normative Convergence Between Goods and Services Trade Law" (2019) 22 Journal of International Economic Law 355. Sometimes, the "blurring" may even be between goods and intellectual property (IP). For instance, sometimes TBT (standardization) and TRIPS (IP) may be intrinsically entangled. See R Pudszun, "Standard Essential Patents and Antitrust Law in the Age of Standardisation and the Internet of Things: Shifting Paradigms" (2019) 50 IIC International Review of Intellectual Property and Competition Law 720.

30 WTO 2018, note 4 above. A useful summary of this Report's description of each of these different disciplines is provided in this PowerPoint presentation: "An In-Depth Look at the World Trade Report 2019" (2018), https://perma.cc/X4NP-DVCE.

31 On the IP angle see WTO 2018, note 4 above; "WIPO Technology Trends 2019: Artificial Intelligence" (2019), https://perma.cc/S85A-P6HK; J Meltzer, "Artificial Intelligence Primer: What Is Needed to Maximize AI's Economic, Social and Trade Opportunities" (2019), https://perma.cc/W8 $3 F-P F F C$ ("For AI to develop also requires an enabling environment that includes new regulation in areas such as AI ethics and data access and revisiting existing laws and regulation in areas such as privacy and intellectual property (IP) rights to ensure that they work for AI").

32 For detailed descriptions of the different reasons why TBT may be relevant to digital trade, see P Cihon, "Standards for AI Governance: International Standards to Enable Global Coordination in AI Research and Development" (2019), https://perma.cc/XL55-D2EU; J Meltzer, note 11 above; J Meltzer, note 16 above; J Meltzer, note 31 above; J Trachtman, "The Internet of Things Cybersecurity Challenge to Trade and Investment: Trust and Verify?" (Draft, 2019), https://perma .cc/NY8R-JYCL; SY Peng, "Private Cybersecurity Standards? Cyberspace Governance, Multistakeholderism, and the (Ir)relevance of the TBT Regime" (2018) 51 Cornell International Law Journal 445. 
Agreement. Novel technologies are being regulated for a variety of policy reasons and in different ways. Here are a few examples.

\section{Internet of Things}

In the last few years, there has been an increase in notified TBT measures dealing with IoT, concerned with their safety, interoperability, national security/cybersecurity, performance and quality. ${ }^{33}$ The challenge is that the IoT is not a single product as such but rather the integrated system of products linked to each other. At the core of the IoT regulatory problem is the very fact that Io $\mathrm{T}$ devices are connected devices, and so even if a single device is compromised, this could risk cyber-intrusion for the whole network.

\section{5G Technology}

Recently notified TBT measures on ${ }_{5} \mathrm{G}$ (fifth-generation cellular network) technology ${ }^{34}$ - the essential technological backbone that will make IoT possible and ubiquitous - indicate different reasons why governments are intervening in this area, including "national security" and "interoperability".

\section{$33 \mathrm{D}$ Printing}

There have also been some recent notifications covering $3 \mathrm{D}$ printing machines/ devices. ${ }^{35}$ Interestingly, some of the objectives behind the notifications have less to do with the safety of the machines themselves and are more about potential illegal misuse (e.g. producing weapons).

\section{Drones}

There has been an increase of notified TBT measures dealing with drones (more specifically, small unmanned aerial vehicles) in the last few years. ${ }^{36}$ Many of these notifications are concerned not only with risks for humans/consumers and interoperability problems, but also with national security risks. Again, the issue may not be the product safety of the drone itself but potential abuses leading to public safety and national security concerns (e.g. recent incidents at airports).

33 G/TBT/N/USA/1597; G/TBT/N/TPKM/399; G/TBT/N/TPKM/40o; G/TBT/N/JPN/610; G/TBT/N/ $\mathrm{KOR} / 776 ; \mathrm{G} / \mathrm{TBT} / \mathrm{N} / \mathrm{EU} / 567$.

34 G/TBT/N/BRA/975; G/TBT/N/BRA/976; G/TBT/N/BRA/977; G/TBT/N/TPKM/399; G/TBT/N/ TPKM/400; G/TBT/N/JPN/627/Add.1; G/TBT/FRA/191 G/TBT/FRA/192; G/TBT/FRA/193.

35 G/TBT/N/THA/479.

${ }_{36}$ G/TBT/N/CHE/233; G/TBT/N/FRA/186; G/TBT/N/FRA/187. 


\section{Autonomous Vehicles}

Not surprisingly, we are also seeing an increase of notified TBT measures dealing with autonomous vehicles, mostly concerned with their safety and performance. ${ }^{37}$ Much has been discussed on autonomous vehicles for private use, but there is a marked increase of use by industry as well.

\section{B The Regulatory Challenge}

Faced with the mindboggling rapidity and complexity of these transformations, governments struggle to react to them in a timely and coordinated fashion. Globally, this may generate a plethora of different regulations and technical standards across countries. This is a problem - in particular, when differences are unnecessary and ill founded - from the perspective not only of its trade impacts but also of consumers, industry and society in general.

TBT disciplines are unique in the way they put into practice the overarching goal of balancing the right to regulate and the avoidance of unnecessary technical barriers. ${ }^{3}$ They are intended to impact members' entire regulatory lifecycle preventively, reactively and self-correctively. Industry requires regulations that address market failures but do not stifle innovation and competitiveness. ${ }^{39}$ The public requires regulation that fosters trust and confidence in products' quality, performance and safety; and trading partners require regulations that are nondiscriminatory, not protectionist and not more trade restrictive than is necessary.

This balance is enshrined in the preamble of the TBT Agreement. As observed by the Appellate Body, the TBT Agreement's "objective of avoiding the creation of unnecessary obstacles to international trade through technical regulations, standards, and conformity assessment procedures [stated in its preamble's fifth recital] is, however, qualified in the sixth recital by the explicit recognition of Members' right to regulate in order to pursue certain legitimate objectives" (Appellate Body Report, US - Clove Cigarettes, para. 94). See also "The WTO Agreement Series: Technical Barriers to Trade", www.wto.org/english/res_e/booksp_e/tbtzrd_e.pdf (hereinafter "TBT Handbook"), at 28 ("the Agreement also gives members the sole prerogative to determine the "level of protection' they deem appropriate under a legitimate objective. At the same time, this right should be balanced against the need to ensure that TBT measures are not prepared, adopted or applied so as to create 'unnecessary obstacles to international trade'. This means that the Agreement does not prohibit all 'obstacles to international trade', but rather only those that are 'unnecessary'.").

39 As already mentioned, international standards can play a positive pivotal role in shaping up national regulatory frameworks for Industry 4.0. As further explained later, the TBT Committee encourages international bodies to observe a set of principles and procedures (the "6 Principles") when developing and adopting international standards. See specifically Principle 4 on Effectiveness and Relevance. G/TBT/1/Rev.9, part I, section III (at 10-12) and annex B (at 37-39). See also E Wijkström and D McDaniels, "International Standards and the WTO TBT Agreement: Improving Governance for Regulatory Alignment" (2013) Staff Working Paper ERSD-2013-o6, at 10, 18; see also TBT Agreement, preamble, third recital and eighth recital. On the "6 Principles", see also notes 43, 53-54, 60 and 65 below. 
This characteristic of balancing between needs makes TBT particularly well suited to addressing regulatory challenges in these times of rapid and radical technological and societal changes.

\section{Transparency on Nascent Regulation}

TBT obligations start early in the regulatory process. The TBT Agreement becomes relevant once the decision to regulate is taken by a member. When this happens, the Agreement subjects members to a series of disciplines aimed at preserving members' policy space while ensuring that the regulation is the least trade-restrictive possible.

\section{Early Notification of Draft Measures Helps Prevent Friction and Fosters Cooperation}

Recognizing the tensions between trade and regulation, the TBT Agreement has important transparency obligations that apply throughout the regulatory lifecycle of a measure. Transparency is the key element of the "preventive" nature of TBT disciplines, which is particularly needed in times of rapid technological change. Unique in the WTO system, the TBT (and SPS) Agreement requires members to notify proposed measures (technical regulations and conformity assessment procedures) and to provide an opportunity for comment. This opens an opportunity for cooperation between regulators to gain valuable feedback toward better-quality regulations, seek clarification and avoid potential trade frictions.

Timing is at the heart of TBT transparency: the notification must take place as early as possible when comments by any stakeholders (including from any other WTO member) can still be meaningfully considered, and possible changes made more easily.

The TBT transparency mechanism is a success story in the WTO. ${ }^{\circ}$ Year on year, an increased number of draft measures are notified to the WTO, demonstrating members' commitment to transparency. A total of 3,337 notifications were submitted in 2019, as compared to 3,000 in 2018. Harnessing the notification process can support a smoother implementation of Industry 4.0 regulations and avoid trade frictions.

2 Technical Barriers to Trade Committee Practices Create Needed Deliberative Spaces

The working practices of the TBT Committee reinforce this "preventive" nature of TBT transparency. When regulations are notified in draft form at early stages of their development, they can be discussed amongst all WTO members.

$4 \circ$ Marianna B. Karttunen, "Transparency in the WTO SPS and TBT Agreements: The Real Jewel in the Crown" (Cambridge, 2020). See also the presentations made at the book launch of 19 June 2020, as the opening event of the WTO’s “TBT@4o Dialogue Series”, www.wto.org/english/tratop_e/tbt_el booklauchtbtspsjewelcrow_e.htm. 
Over the years, the TBT Committee has been used by members to raise "specific trade concerns" (STCs) with respect to each other's TBT measures. This practice, combined with the early notification of draft measures, facilitates regulatory dialogue, helps ensure that other views are taken into consideration and, in the best cases, creates opportunities for regulatory cooperation, which can in turn lead to improved and more effective regulations. ${ }^{41}$

Since all this takes place in the multilateral setting of the TBT Committee, it carries an additional "preventive" benefit; one especially important with respect to nascent regulations addressing challenges stemming from new and rapidly evolving technologies, including Industry 4.o. Concerns raised in the TBT Committee also serve as a bellwether on new regulatory trends and point to areas where early dialogue is required on evolving regulation. In fact, as far back as the early zooos the Committee was already discussing concerns with Internet-related regulations. ${ }^{42}$

\section{Transparency Is Not a "One-Off" Obligation}

But not everything can be addressed preventively. Regulations are based on issues, risks and techno-scientific knowledge available at the time of their development and adoption. Risks can change, sometimes rapidly and continuously so. Regulations may therefore need to change accordingly, and these changes may sometimes themselves constitute trade barriers.

The TBT Agreement contains disciplines aimed at situations when regulations need to evolve and adapt. ${ }^{43}$ For instance, Article 2.3 of the Agreement states that measures may not be maintained if the circumstances or objectives giving rise to their adoption no longer exist or can be addressed in a less trade-restrictive manner.

In other words, if, upon reassessment, in light of new scientific (or other relevant) information, a perceived risk is deemed to be nonexistent, it may be necessary to review the measure. ${ }^{44}$ For instance, the TBT Committee recommended that members submit "follow-up notifications" to track the progress of a measure through the

${ }^{41}$ For a recent discussion about the important role of STCs as ways for addressing regulatory trade frictions cooperatively rather than litigiously, see "WTO TBT Committee and regulatory measures: prevention, not litigation”, TBT@4o Dialogue Series (2 September 2020),www.wto.org/english/ tratop_e/tbt_e/tbt_t40_20920_e.htm.

42 "Korea: Regulation on Wireless Internet Platform for Interoperability - STC n. 89", G/TBT/M/29, para. $54-56$.

43 This principle is equally applicable to international standard-setting processes. In fact, it is highly relevant because under the TBT Agreement international standards should normally be the basis of regulations, and because of the special role international standards should and will play in Industry 4.0 regulations. As further explained later, the TBT Committee has provided some guidance and principles on various aspects related to international standard-setting. One of these principles "Effectiveness and Relevance" (Principle 4) - stresses the importance of international standardizing bodies taking account of "relevant regulatory or market needs, as feasible and appropriate, as well as scientific and technological developments in the elaboration of standards". On the "6 Principles", see also note 39 above, and $53-54,60$ and 65 below.

44 TBT Handbook, note 38 above. 
regulatory lifecycle, and to provide new comment periods following substantial revisions. The Committee has also recommended that the availability of the final adopted text should be notified as a follow-up to the original notification.

In the ideal case, transparency by fostering regulatory cooperation can help avoid technical barriers to trade and improve the quality of the regulation. As governments start to regulate AI and other technologies driving Industry 4.0, it becomes even more important to utilize the tools provided by the TBT Agreement to shed more light on emerging national governance frameworks.

\section{Data and Dataflows: Is There a Technical Barriers to Trade Angle?}

Despite competitive tensions, international cooperation is needed if Industry 4.0 is to succeed. AI needs to be able to access vast amounts of data. Volume matters because machine learning needs to be able to incorporate into future predictions as many past outcomes as possible. ${ }^{45}$ Much of this data is obtained from both national and cross-border Internet activity and digital platforms. Businesses and governments are also important sources of data. The McKinsey Global Institute estimates that in 2014 global data flows were more valuable than trade in goods, ${ }^{46}$ and PricewaterhouseCoopers predicts that by 2030, AI could raise global GDP by over $\$ 15$ trillion. ${ }^{47}$

Discussions on e-commerce at the WTO are illustrative of the challenges faced on the global governance of data and the implications for Industry 4.0. At the risk of missing out important nuances, views on the question of data appear to fall into three camps.

There are those who are generally opposed to data localization requirements and restrictions on cross-border data flows, unless such measures would fall under limited exceptions. There are others who, while in general opposing these restrictions, wish to reserve the right to adopt appropriate safeguards to protect personal data and privacy, including rules on the cross-border transfer of personal data. Finally, some appear to favor wide latitude to exercise cyberspace sovereignty in pursuit of public policy objectives. ${ }^{8}$

While the TBT Agreement's scope is on trade in goods and not on cross-border data flows per se, there are some important data-related considerations. With the IoT, products have embedded sensors that collect, transmit and exchange information in real time over a network regardless of their location. Since such sensors and the accompanying source code could be said to be a characteristic of the product,

45 Meltzer, note 31 above.

$4^{6}$ Meltzer, note 11 above, at 23.

47 Ibid.

$4^{8} \quad$ Following the categorization by Niall Meagher and Vitaly Pogoretskyy in the presentation on WTO Negotiations on E-commerce: General Overview - Workshop for the Informal Group of Developing Countries (AWCL, 16 September 2019) (on file with the author). 
any technical regulation on source codes would probably be within the scope of the TBT Agreement.

Members in the TBT Committee have discussed around sixteen "specific trade concerns" related to a range of "cybersecurity measures", covering ITC products and network equipment, vehicles, civil aviation, banking and insurance, amongst other sectors. Concerned members voiced issues about requirements that could discriminate against foreign technology and equipment, lack of clarity of the measures, inconsistency with international standards and best practices and the need for duplicative in-country testing of imported products. ${ }^{49}$

The challenge is: how do we square the right to take measures necessary for the protection of essential security interests and not create unnecessary obstacles to international trade? Here, there are important principles and obligations in the TBT Agreement that are worth recalling, especially in terms of promoting good regulatory practices and regulatory cooperation, and the use of international standards.

\section{E Role of International Standards in Support of Regulatory Alignment}

International standards are critical for achieving the full potential of Industry 4.O, while avoiding unnecessary barriers to trade in these technologies. ${ }^{50}$ Alignment of regulations for connected devices to international standards will facilitate trade by providing a common benchmark, enhancing competition and lowering prices for consumers.

The TBT Agreement is a driving force for harmonization and coordination at a global scale, through its provisions that strongly promote alignment of national regulations to international standards. The pivotal role of international standards to the attainment of the TBT Agreement's principles and objectives is already reflected in various parts of its preamble. There, the Agreement "encourage[s] the development of international standards", listing "important contributions" these documents can make to "improving efficiency of production and facilitating the conduct of international trade" and promoting "the transfer of technology from developed to developing countries". ${ }^{1}$

$49 \mathrm{G} / \mathrm{TBT} / \mathrm{M} / 71$, paras. 2.9-2.22; G/TBT/M/72, paras. 3.4-3.10; G/TBT/M/73, paras. 2.4-2.6; G/TBT/M/ 72, paras. 3.27-3.30; G/TBT/M/72, paras. 3.31-3.35; G/TBT/M/72, paras. 3.11-3.17; G/TBT/M/67, paras. 2.51-2.56; G/TBT/M/65, paras. 2.16-2.22; G/TBT/M/64/Rev.1, paras. 2.53-2.54; G/TBT/M/57, paras. 76-79; G/TBT/M/55, paras. 39-42; G/TBT/M/53, paras. 85-96; G/TBT/M/52, paras. 9-14; G/ TBT/M/48, paras. 49-53; G/TBT/M/44, paras. 34-37; G/TBT/M/32.

50 On international standards generally, see TBT Handbook, note 38 above, at $33-36$; see also "Facilitating Trade Through Regulatory Cooperation: The Case of the WTO's TBT/SPS Agreements and Committees", https://perma.cc/WHoN-Q 5 VX.

51 "International standards can be seen as 'evidence-based' documents codifying scientific and technical knowledge developed at the global level. Their development and use can thus be an important means of disseminating knowledge and fostering innovation." TBT Handbook, note 38 above, at 34 . See also WTO 2020, note 10 above, at 135-137 and 151-152 (stating, for instance, that the TBT Agreement also 


\section{Alignment with International Standards}

More specifically, the Agreement:

(i) requires members to use relevant international standards as a basis for national regulations (except when the international standard would be ineffective or inappropriate to accomplish a member's legitimate objective);

(ii) incentivizes members to fully harmonize measures with international standards (presuming TBT consistency); and

(iii) strongly encourages members to participate in the development of international standards.

Therefore, the TBT Agreement acts as a catalyst for alignment of national product regulations based on voluntary international standards set by specialized non-WTO bodies. In principle, the use of international standards by governments brings regulatory requirements and systems closer to one another, thereby reducing the prevalence of unnecessary differences. ${ }^{52}$

\section{No Definition of International Standards but Six Principles Instead}

But there is a catch. The TBT Agreement does not contain a definition of international standards. Nor does it contain a list of recognized international standardizing bodies, as is the case under the SPS Agreement. This has created some debate and tension in the WTO, given the degree of uncertainty about the identification of the benchmark for alignment. But at the same time it has also given members flexibility.

In order to provide additional guidance, in 2000 the TBT Committee took a decision on the "Principles for the Development of International Standards, Guides and Recommendations, with Relation to Articles 2, 5 and Annex 3 of the TBT Agreement". ${ }^{3}$ This decision, commonly known as the "six principles", encourages international standard-setting bodies to observe a set of principles and procedures when international standards, guides and recommendations are elaborated to ensure: (i) transparency; (ii) openness; (iii) impartiality and consensus; (iv) effectiveness and relevance; (v) coherence; and (vi) the development dimension. ${ }^{54}$

recognizes the pivotal role of technical standards, in particular of international standards, in "technology development and dissemination"). Ibid., at 135.

52 See Wijkström and McDaniels, note 39 above.

53 G/TBT/1/Rev.9, part I, section III (at 10-12) and Annex B (at 37-39). On the "6 Principles", see also notes 39 and 43 above, and 54,60 and 65 below.

54 For a recent appraisal of the relevance of the "6 Principles" since its adoption more than twenty years ago, and on whether they still "remain fit for purpose in a world of rapid change", see "TBT Committee's Six Principles for the development of international standards: Are they still relevant?" TBT@40 Dialogue Series (14 October 2020).www.wto.org/english/tratop_e/tbt_e/tbt_six_princip les_e.htm. 
International standards that are developed in line with these principles are more likely to be considered as "relevant international standards" for the purposes of the TBT Agreement. Adherence to these so-called six principles will continue to be vital for standardization with respect to Industry 4.0.55

The process of international harmonization set out in the Agreement is not, however, a rigid one. It gives members space to deviate from international standards under certain conditions. The TBT Agreement gives members the leeway not to use international standards as a basis for a regulation if they would be "ineffective" or "inappropriate". For instance, "fundamental climatic or geographic factors" or "fundamental technological problems" may sometimes render an existing international standard an unsuitable basis for properly addressing the objectives of a regulation a member intends to prepare and adopt. ${ }^{56}$

\section{An Incentive to Use International Standards}

The Agreement also provides a strong incentive to use international standards. When technical regulations are "in accordance with" relevant international standards, they are "rebuttably presumed" not to create unnecessary obstacles to international trade (i.e. they are presumed not to be more trade-restrictive than necessary and thus consistent with Article 2.2). It provides a "safe haven" for measures conforming to international standards with the objective of "harmonizing" technical regulations, conformity assessment procedures (CAPs) and (national) standards "on as wide a basis as possible". ${ }^{57}$ The Agreement puts a particular emphasis on the fact that this goal can only be attained if the international standard-setting process is as inclusive and participative as possible, in particular by developing country members..$^{5}$ In other words, "Members shall play a full part, within the limits of their resources, in the preparation by appropriate international standardizing bodies of international standards, guides and recommendations relevant to technical regulations or conformity assessment procedures they adopted or are expected to

55 See also WTO 2020, note 10 above, at 136 (referring to evidence that, in fact, the "six principles" have benefited the digital age since its inception: "Karachalios and McCabe (2013) argue that the success of the internet has benefitted from the bottom-up, globally open, market-driven system of standardization as supported by the TBT Committee's [6 Principles]").

${ }^{6}$ Under the second part of Article 2.4 of the TBT Agreement, a member may depart from a relevant international standard when it would be an "ineffective or inappropriate means for the fulfilment of the legitimate objectives pursued" by the domestic regulation. In addition, on special and differential treatment, see Art. 12.4.

57 As stated in Articles 2.6, 5.5 and Annex 3.G, respectively.

$5^{8}$ See TBT Technical Assistance (TA) and Special and Differential Treatment (S\&D) provisions on improving participation in international standard-setting: Articles 11.2, 12.5 and 12.6. See also Walshe et al., "AI and Big Data Standardization: Contributing to United Nations Sustainable Development Goals", Journal of ICT, 8_2 (2020), 77-106, at 88 (stating that international standards "provide a universal language, thus breaking down technical barriers to international trade allowing developing countries to compete more easily in the global marketplace"). 
adopt" 59 This has been challenging for many developing countries and it could be even more so with rapidly developing standards for new technologies. ${ }^{6 \circ}$

\section{Voluntary vs. Mandatory: To What Extent Is This an Issue?}

One concern that is frequently highlighted is the implications of being a voluntary national standard or a "mandatory" technical regulation. This is an important issue for Industry 4.0 as there are many actors out there developing standards that could potentially shape the sector. The disciplines on technical regulations arguably bite deeper, but it is worth recalling that there are also disciplines in the TBT Agreement on "voluntary" national standards. These disciplines, which are a combination of Article 4 and Annex 3 to the Agreement (the Code of Good Practice for the Preparation, Adoption and Applications of Standards - "Code of Good Practice" ${ }^{\prime 1}$ ), contain substantive provisions on discrimination, trade restrictiveness, use of international standards and so on, largely mirroring those for technical regulations.

The obligation works in a two-pronged manner: (i) members shall ensure that their central government standardizing bodies have to accept and comply with Annex 3 of the Code of Good Practice; and (ii) members shall take reasonable measures as may be available to them to ensure that their local (as well as regional) and nongovernmental standardizing bodies also comply and accept. So, while Annex 3 is open to acceptance by any standardizing body, which includes a "nongovernmental body", Article 4 creates an obligation on members to ensure that they do so. Since Article 14.4 on dispute settlement covers Article 4, this avenue could be pursued where a member considers that another member has not achieved satisfactory results.

A question that is different from whether there are disciplines on "voluntary" standards is what is to be understood by a "non-governmental body". The definition

59 TBT Agreement, Articles 2.6 and 5.5.

6o In order to address such challenges, the TBT Agreement contains detailed provisions tailored specifically to developing and least-developed members on Technical Assistance (Article 11) and Special and Differential Treatment (Article 12). Also relevant is the TBT Committee "6 Principle" decision on international standards, which addresses these challenges in "Principle 6" (on "Development Dimension"). On the "6 Principles", see notes 39, 43, 53-54 above, and 65 below.

61 Under Article 4.1 (first sentence), members shall ensure that their "central government standardizing bodies" not only accept but, more importantly, also comply with all principles and obligations of the Code of Good Practice (Annex 3). Such obligations include, for instance, that standards adopted by central bodies shall: not be discriminatory (Annex 3.D); not create "unnecessary obstacles to international to trade" (Annex 3.E); and be based on "international standards" (Annex 3.F). The Code (see Annex 3.B) also covers standards adopted by "local government bodies" and "non-governmental bodies" as well as those by "regional standardizing bodies". However, members' obligations with respect to these other bodies are less stringent: members shall only "take such reasonable measures as may be available to them" to ensure that these bodies accept and comply with the Code (Article 4.1, second sentence). "Central government", "local", "non-governmental" and "regional" bodies are defined in Annex 1 of the Agreement. 
of a nongovernmental body in the Agreement is illustrative. It defines it in the negative as a "body other than a central government body or a local government body, including a non-governmental body which has legal power to enforce a technical regulation". ${ }^{62}$ What about other nongovernmental bodies; that is, those that do not have legal power? And what should be understood by "nongovernmental"? These are issues for further consideration.

\section{F Improving Coherence}

Coherence in standards development is a major challenge for Industry 4.o. Entire batches of standards are being developed to underpin AI, the IoT, blockchain and autonomous systems (e.g. cars, trucks, trains, drones), to name just a few. ${ }^{63}$ These standards will all need to "talk" to each other, and interoperability will be critical to ensure performance, privacy, safety, etc. Imagine one autonomous vehicle trying to avoid an accident with another autonomous vehicle. If the other vehicle is following a different standard, the vehicles will not be able to communicate, and this could inadvertently provoke a crash. ${ }^{64}$ So, as this process unfolds, standards will be essential to keep the "parts" interoperable and contributing to the "whole".

If, for example, two international bodies decide, independently and without talking to each other, to develop differing standards for addressing issues related to the safety of autonomous vehicles, they may well end up adopting two significantly different - or worse, conflicting - international standards addressing the same issue. Trade will be very difficult, if not impossible, between countries that have not used the same international standard as a basis for their regulations.

The TBT Committee "six principles" highlight the importance of coherence, ${ }^{65}$ in order to avoid duplication or overlap between the work of international standardizing bodies. Cooperation and coordination are essential. A lack of coherence is also a barrier to participation by developing countries in international standardization as their scarce resources cannot cover participation in duplicative processes.

Lock-in and path dependencies in standards for one technology can also quickly lead to fragmentation and duplication in standards for other technologies. This translates to higher trade costs and impediments to innovation. Forward-looking cooperation between standards development organizations and between regulators can help chart a path toward convergence.

62

63 WTO 2020 , note 10 above, at 135 (discussing the relevance of "technical standards" in these areas).

64 "DDG Wolff Urges Standards Bodies to Boost Support for Multilateral Trading” (WTO, 28 September 2018), https://perma.cc/9XJM-H97P.

65 As already mentioned above, another principle of particular relevance for Industry 4.0 is "Effectiveness and Relevance" (Principle 4), which complements the need to attain "coherence". See in particular recommendations (a) to (c). On the "6 Principles", see notes 39, 43, 53-54 and 60 above. 


\section{G Good Regulatory Practice}

Good regulatory practice (GRP) describes best practices and procedures developed by governments and organizations to improve the quality of regulation. ${ }^{66}$ It must therefore also be an indispensable component of the Industry 4.0 regulatory process. A key feature of the fourth industrial revolution are technologies that straddle multiple sectors, jurisdictions and institutions. Regulation, on the other hand, tends to be organized along traditional sectoral lines. As new regulations are formulated, or existing ones redesigned, the impact on trade could be considerable. GRP provides governments with a toolkit of approaches and processes that can help them identify and address the trade impacts of their regulatory action. ${ }^{67}$

Examples of GRP include internal coordination (whole-of-government approach), transparency and public consultations, and regulatory impact assessment. Much work has been done in this area, both at the WTO and elsewhere, including in the context of the Asia-Pacific Economic Cooperation (APEC), the Organisation for Economic Co-operation and Development (OECD) and the World Bank. ${ }^{68}$ Application of GRP can help ensure the design of high-quality, costeffective regulations that are consistent with the goal of open trade. Moreover, the wider dissemination of GRP can contribute to the establishment of a common, predictable framework for regulatory intervention, thereby facilitating international regulatory cooperation and harmonization. ${ }^{69}$

The TBT Committee has recognized that "GRP can contribute to the improved and effective implementation of the substantive obligations under the TBT Agreement" ${ }^{7 \circ}$ GRP discussions in the TBT Committee have emphasized the transparency and accountability of regulatory processes. ${ }^{71}$ Strengthening transparency and accountability can help avoid unnecessarily trade-restrictive regulatory outcomes. Other areas of GRP considered by the TBT Committee include analysis and review of regulatory alternatives (including the option not to regulate) and the design of regulations, including the advantages of simple, responsive and flexible regulations. Members have also stressed that GRP is an important element of capacity-building initiatives $^{72}$ and that preparing GRP guidelines could be particularly helpful for developing countries. ${ }^{73}$

66 See TBT Handbook, note 38 above, at 30.

${ }^{67}$ See R Basedow and C Kauffmann, "International Trade and Good Regulatory Practices: Assessing the Trade Impacts of Regulation” (2016) OECD Regulatory Policy Working Papers No. 4, https://perma .cc/F $44 \mathrm{~S}-\mathrm{YFN}_{2}$.

68 Ibid

69 G/TBT/26, para. 14. See also "Facilitating Trade through Regulatory Co-operation: The Case of the WTO's TBT/SPS Agreements and Committees" (WTO-OECD 2019), at 9-10 (hereinafter "WTOOECD 2019").

$70 \mathrm{G} / \mathrm{TBT} / 26$, para. 5, at 2. See also WTO-OECD 2019, note 69 above, at 10.

${ }^{71} \mathrm{G} / \mathrm{TBT} / 32$, para. 4.

72 G/TBT/26, para. 59 .

73 See TBT Handbook, note 38 above, at 30-32. See also, generally, WTO-OECD 2019, note 69 above. 
The TBT Agreement's provisions on transparency and discussions on GRP are closely linked. For instance, "early notice", notification, comments, publication and entry into force are all processes that should lead to better regulation. Incorporating the transparency processes of the TBT Agreement into the regulatory lifecycle of a specific measure is a powerful means of fostering GRP, which has transparency and consultation as one of its fundamental components. ${ }^{74}$ At the same time, greater utilization of GRP could help contribute to avoiding unnecessary and unintentional regulatory barriers to trade.

\section{H Regulatory Dialogue and Cooperation}

Besides harmonization via international standard-setting processes, the TBT Agreement provides members with "sign-posts" to engage in other forms of cooperation through various mechanisms, such as "equivalence" or "arrangements for conformity assessment". ${ }^{75}$ These are additional mechanisms for encouraging the reduction of regulatory diversity and associated trade $\operatorname{costs}^{76}-$ key challenges of Industry 4.0.

Equivalence refers to an arrangement in which members recognize that, although each other's product specifications and rules are different, they achieve the same result. When this happens, they can decide to accept the rules of the trading partner as "equivalent". 77

This facilitates trade by allowing firms to produce according to domestic requirements and still directly access foreign markets without having to meet another set of requirements. It does not require regulations to be changed from the preferred domestic policy. The way that members choose to cooperate through equivalence agreements may vary depending on trade flows, their respective levels of protection, the costs of demonstrating achievement of the appropriate level of protection in light of risk and the possibility of unilateral or mutual recognition of equivalence. ${ }^{78}$

The TBT Agreement sets out a framework for members to reach "equivalence agreements" on their TBT-related technical regulations. ${ }^{79}$ The Agreement does this not by requiring but by encouraging members to "give positive consideration to accepting as equivalent technical regulations of other Members, even if these regulations differ from their own, provided they are satisfied that these regulations adequately fulfil the objectives of their own regulations" ${ }^{80}$

WTO-OECD 2019, note 69 above, at 44.

$7^{6}$ Ibid.

77 Ibid.

$7^{8}$ Ibid.

79 Ibid., at 45.

8o TBT Agreement, Article 2.7. See also WTR 2020, note 10 above, at 136 and 151 (stressing the importance of TBT"s encouragement to “equivalence”). 


\section{Facilitating Acceptance of Conformity Assessment Results}

Divergent systems that trading partners use to verify conformity to applicable standards and regulations can create impediments to trade. ${ }^{81}$ Around half of specific trade concerns raised at the TBT Committee over the last ten years have been on CAP. Duplication of testing and certification (due to nonrecognition of results) is a frequent source of trade friction. It is likely that conformity assessment will become even more complex with Industry 4.0. ${ }^{82}$ Developing countries face particular challenges in the digital age, as systems and laboratories are not always available or as effective as they could be. ${ }^{83}$

The TBT Agreement, of course, requires members to ensure that their CAPs, among other obligations, do not create unnecessary obstacles to international trade. ${ }^{84}$ But the way to achieve this result is far from obvious.

Governments greatly prize their freedom to regulate as a sovereign right and they have a responsibility to do so. No government wants to be told by another government (let alone an international organization) how to protect their security interests, consumers or the environment, or what tests or certificates to accept and from whom, or what results to follow. They may be unwilling to accept a test report or certificate from a foreign body that they do not know or may not trust.

Moreover, limited development of National Quality Infrastructure (e.g. standardization, metrology, accreditation, conformity assessment procedures), supporting laws and policy frameworks in some economies may limit options available to regulators when choosing their conformity assessment procedures. ${ }^{85}$

This can make it difficult to strike the balance between, on the one hand, the strictness of the procedures put in place to assess conformity to a given regulation's objectives, and, on the other, the risks that "nonconformity" with those objectives would create. ${ }^{86}$ This challenge is not unique to Industry 4.O-related products, but achieving the appropriate balance may be particularly difficult for new technologies for which the risks are still not fully understood. Here, the TBT Agreement encourages the use of several tools to build trust and confidence.

These include recognition of conformity assessment results and the use of international and regional systems for conformity assessment. The TBT Agreement encourages members to recognize the results of CAP of other members, recognizing that this needs to be built upon cooperation between them, including in respect of the adequate and enduring technical competence of the relevant conformity

81

82 See J Rosenberg, "Conformity Assessment: An Industry Perspective" (2015), https://perma.cc/6LUHT6BL.

83 See B Zhai and W Aranki, "Quality Infrastructure (QI): A Rising Topic for Development" (IAF Outlook, 30 June 2020), https://perma.cc/CKS9-2KA9.

84 TBT Agreement, Article 5.1.2. See also WTO-OECD 2019, note 69 above, at 45.

85 WTO-OECD 2019 , note 69 above, at 45 .

86 Ibid. 
assessment bodies in the exporting member. ${ }^{87}$ The Agreement provides a basis for cooperation, stating that prior consultations might be needed to arrive at a mutually satisfactory understanding on recognition. ${ }^{88}$

The TBT Agreement mentions accreditation as one means to build trust and confidence in the technical competence of foreign bodies providing CAP results. ${ }^{89}$ It also encourages members to allow foreign conformity assessment bodies to participate in their national conformity assessment procedures on a national treatment and most-favored-nation basis. ${ }^{90}$ The potential of accreditation to lower the costs of conformity assessment by eliminating the need for duplicative tests and certifications is not reached automatically: regulators have to be willing to rely on accreditation within their conformity assessment schemes.

Further, the TBT Agreement encourages members to enter into negotiations to conclude agreements on mutual recognition (MRAs) of the results of each other's conformity assessment procedures..$^{91}$ MRAs are one regulatory cooperation mechanism that allows parties to recognize specific results (e.g. test reports or certificates) in specific sectors. ${ }^{9^{2}}$ While little is known about the actual implementation and functioning of MRAs, they can require significant time and costs to negotiate and maintain. ${ }^{93}$ MRAs have been most successful in specific sectors like electrical and electronic products (e.g. the Association of Southeast Asian Nations MRA).

The TBT Agreement requires members, wherever practicable, to formulate and adopt, as well as participate as members of, international systems for conformity assessment. ${ }^{94}$ This can help to strengthen regional and international regulatory cooperation between members in the area of CAP. .95

These types of international and regional systems have grown in importance since the entry into force of the TBT Agreement in 1995. In the TBT Committee, members have discussed a range of systems based on arrangements between accreditation and conformity assessment bodies, including those operated by the International Laboratory Accreditation Cooperation, the International Accreditation Forum and the International Electrotechnical Commission (e.g. the IECEE CB scheme ${ }^{96}$ ), as well as other organizations. In the TBT Committee,

Ibid., at 46 .

TBT Agreement, Article 6.1. See also WTO-OECD 2019, note 69 above, at 46.

TBT Agreement, Article 6.1.1. See also WTO-OECD 2019, note 69 above, at 46 .

TBT Agreement, Article 6.4. See also WTO-OECD 2019, note 69 above, at 46.

TBT Agreement, Article 6.3. See also WTO-OECD 2019, note 69 above, at 46.

See also WTO 2020, note 10 above, at 135-136 (stressing the importance of TBT rules on MRAs, including as useful "tools by which the multilateral trading system fosters co-operation on digital technologies").

See also WTO-OECD 2019, note 69 above, at 46.

TBT Agreement, Article 9.1. See also WTO-OECD 2019, note 69 above, at 46.

See also WTO-OECD 2019, note 69 above, at 46.

International Electrotechnical Commission for Electrical Equipment Certification Body scheme. This is an international system for mutual acceptance of test reports and certificates dealing with the safety of electrical and electronic components, equipment and products. 
members have discussed how to increase regulators' reliance on these types of systems to facilitate trade. ${ }^{97}$

\section{CONCLUDING REMARKS}

There is much in the TBT toolkit of disciplines, decisions, recommendations and practices that can be used to support Industry 4.0 by avoiding unnecessary regulatory diversity and reducing trade costs. Yet the converging and multidisciplinary nature of Industry 4.0, as well as the fast pace of technological changes associated with it, might mean that simply emphasizing better application of WTO rules by each member may not be enough.

Industry 4.0 instead requires broad, concerted, cooperative regulatory discussions; it also requires these discussions to be flexible, as well as both preventive (focus on drafts) and forward looking (detecting trends, constant updating, revisions, etc.), so as to minimize unnecessary barriers to trade. The WTO TBT Agreement and Committee practice could be used to support cooperation. But there are also issues that will need further consideration:

- Transparency is key, particularly given TBT transparency's unique preventive and self-corrective nature. How can these be better used and harnessed so as to shed more light on Industry 4.o-related regulation?

- International standardization is also key for Industry 4.0 regulatory processes. But sometimes full harmonization is not possible, or even desirable (e.g. difficult to harmonize nontechnical, societal issues like morality, religion and privacy, now also forming the basis of Industry 4 .0 regulations on both goods and services). WTO will not be the place to set standards, but the TBT decision on six principles can help guide such development. However, we also need to recognize that international standardization will have difficulty in harmonizing cases where there are widely divergent underlying values and approaches. What can be done in the absence of international standards?

- This brings into focus other tools such as regulatory cooperation and good regulatory practices. Industry 4 .o regulation is dynamic and ever-evolving: there is a pressing need to establish a constant dialogue for better identifying what the convergences and differences in Industry 4.0 are and to discuss how to deal with some of them. How can we ensure coherence, avoid measures that are unnecessary and cope with those that are necessary?

- Some Industry 4.0 issues have already been raised at the TBT Committee through the notification and specific trade concerns process. Should and can more be done in terms of Industry 4.0 issues? This is a matter for further deliberation by WTO members. Some issues might lend themselves more to horizontal approaches (decisions and recommendations) as well as vertically

97 G/TBT/1/Rev.13, Section 3.1, at 14. See also WTO-OECD 2019, note 69 above, at 46. 
(in terms of how best to improve the STC process - a topic already under consideration in discussions on WTO reform).

- There is also the question of the cross-cutting nature of the challenge of convergence. Apart from the TBT Committee, Industry 4.o-related issues are surfacing either in whole or in part in different bodies and processes in the WTO (e.g. TRIPS Council; Joint Statement on E-Commerce; E-commerce Work Program; the GATS). How do we ensure coherence in approaches and avoid fragmentation in the discussion?

There are undoubtedly many more issues, many of which have already been raised in this book. In the future, AI will have written and possibly delivered this address. And it will undoubtedly have done a better job. And, very possibly, AI will also have negotiated the trade agreements that are needed to help it flourish. Until then, we will have to rely on the one thing that has helped us as humans, with all our limitations, to survive and thrive - our ability, despite all the dissonance on trade, to develop instruments for large-scale, vast networks of cooperation. 